\title{
Methadone versus buprenorphine: data detected from Caltanissetta SER.T
}

\author{
Fabio Venturella, ${ }^{1}$ Giulia Cancellieri, ${ }^{2}$ Marco Giammanco, ${ }^{3}$ Anastasia Valentina Liga, ${ }^{2}$ \\ Francesca Mortillaro, ${ }^{2}$ Annamaria Di Carlo ${ }^{2}$ \\ ${ }^{1}$ Biological, Chemical, and Pharmaceutical Science and Technologies Department, University of Palermo; ${ }^{2}$ Pharmacy \\ Department, University of Palermo; ${ }^{3}$ Surgical, Oncological and Stomatological Disciplines Department, University of \\ Palermo, Italy
}

\begin{abstract}
In last years, heroin-addicted have exponentially increased: this has made it necessary to identify a pharmacological strategy as effective as possible. With this purpose, a statistical investigation was conducted in a sample of individuals, aged between 18 and 50 . They were diagnosed and subjected to different treatments at Ser.T of Caltanissetta (Sicily-Italy) during the period 2013-2017. The analyzed patients were treated with three different pharmacological therapy: methadone $0.1 \%$, methadone $0.5 \%$, buprenorphine and suboxone. We obtained percentages of responders, low responders and non-responders patients from data processing, based on used therapy. Considering pharmacological responses of the sample examined, it is possible to observe that the treatment with buprenorphine has led to $71.98 \%$ of responders subjects, $23.52 \%$ of low responders and $4.5 \%$ of non-responders. Instead, the administration of methadone $0.1 \%$ has produced $82.82 \%$ of responders subjects, $11.08 \%$ of low responders, $6.1 \%$ of nonresponders. The therapy with methadone $0.5 \%$ has resulted $88.98 \%$ of responders subjects, $7.8 \%$ of low responders, $3.22 \%$ of nonresponders. Finally, through the administration of suboxone, we obtained $86.34 \%$ of responders subjects, $9.84 \%$ of low responders and $3.82 \%$ of non responders. In conclusion, although it has emerged that treatment with methadone $0.5 \%$ is the most successful therapy, it is preferable to use suboxone (except in relapsing
\end{abstract}

Correspondence: Anastasia Valentina Liga, Pharmacy Department, University of Palermo, Via Tommaso Natale 42, 90147, Palermo, Sicily, Italy.

Tel.: +39.3279457023.

E-mail: ania.liga90the@gmail.com

Key words: heroin; methadone; suboxone.

Conflict of Interest: The Authors declare no potential conflict of interests.

Received for publication: 14 June 2019.

Accepted for publication: 1 October 2019.

${ }^{\circ}$ Copyright: the Author(s), 2020

Licensee PAGEPress, Italy

Journal of Biological Research 2020; 93:8345

doi:10.4081/jbr.2020.8345

This article is distributed under the terms of the Creative Commons Attribution Noncommercial License (by-nc 4.0) which permits any noncommercial use, distribution, and reproduction in any medium, provided the original author(s) and source are credited. subjects) since it has also produced a high number of responders subjects and a good safety profile for heroin addicted patients.

\section{Introduction}

This analysis is included in the prevention project called Addiction and Information about the New and Rape Drugs, Addictions and Amateur Doping sponsored by University of Palermo, Municipality of Palermo, Federfarma - Utifarma and Health Department of Sicily Region. The purpose of the study was to estabilish and, also, to evaluate the most successful drug treatment in cessation therapy. There are two reasons that led us to carry on this work. The first concerns the increase in the percentage of subjects, especially adolescents, who in recent abuse heroin. This is due to the introduction of new ways of taking heroin by inhalation, heroin is sniffed or smoked, which gives the perception of less danger than intravenous route of administration. The second motivation lies in the gravity that heroin abuse determines in the subject that he assumes it both individually and socially. Heroin indirectly stimulates the Nucleus accumbens, an area that is part so-called gratification circuit together with the ventral tegmental area. Chronic exposure to the substance causes neurons in this area to become less responsive to afferents coming from the prefrontal cortex, an area that plays a fundamental role in cognitive processes and planning. Such changes in neuronal circuits, in the long run, have the effect of attention, learning, memory, executive functions and work performance. The effects from the behavioral point of view are the strong desire or craving that pushes him to take the substance and focus his whole existence in the search for it, abandoning his work, school and family commitments and sometimes even going to commit criminal acts. ${ }^{1-7}$

\section{Materials and Methods}

During the period between 2013 and 2017, we conducted a statistical survey at the Ser.T of Caltanissetta in order to assess the best drug therapy to be undertaken for a path of dissuefaction in heroinin subjects.

The Ser.T of Caltanissetta belongs to the territorial area of the ASP 2 of Caltanissetta and includes the municipalities of Gela, Mussomeli and San Cataldo, but also neighboring municipalities such as Villalba, Vallelunga Pratameno, Sutera, Campofranco, Niscemi, Mazzarino, Riesi, Sommatino, Serradifalco, Santa Caterina Villarmosa, Butera, Delia, Milena, Resuttano, Marianopoli, Montedoro, Acquaviva Platani and Bompensiere.

The study was conducted on approximately 1200 patients, aged 
between 18 and 50 years, predominantly male (91\% men vs. 9\% women), addicted to heroin or heroin and other substances (cannabis, cocaine, alcohol, etc).

They were divided into groups (numerically different) and treated with 4 different pharmacological treatments: i) Methadone 0.1\%; ii) Methadone $0.5 \%$; iii) Buprenorphine; iv) Suboxone. Each of these pharmacological treatments has been associated with psychotherapeutic, psychoeducational and rehabilitation interventions.

For the processing of data was adopted the graphic representation method, in order to establish the percentage of responders, low responders and non-responders to the various treatments performed. Note that: i) responders are those who show drug-free $>60 \%$; ii) low responders show drug-free between 30 and $60 \%$; iii) non-responders show drug-free $<30 \%$.

\section{Results}

The extrapolation of data shows that the number of heroin addicted has increased in the five-year period analyzed, with a

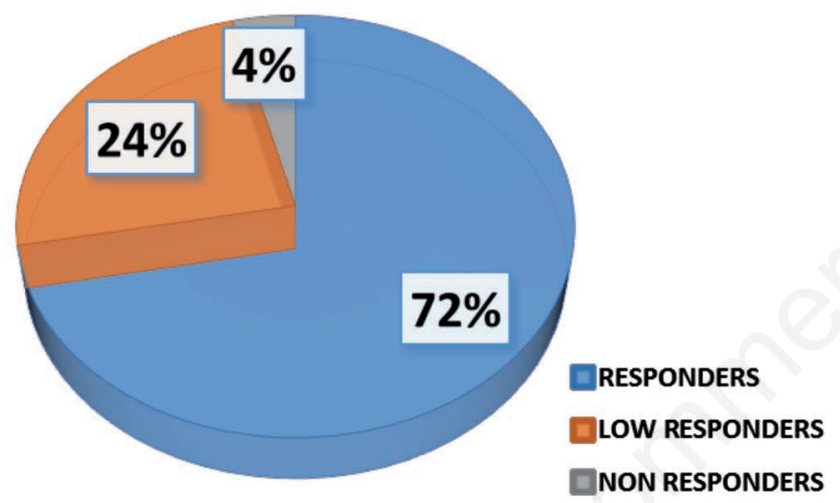

Figure 1. The treatment with buprenorphine led to $71.98 \%$ of responders subjects, $23.52 \%$ low responders, $4.5 \%$ nonresponders.

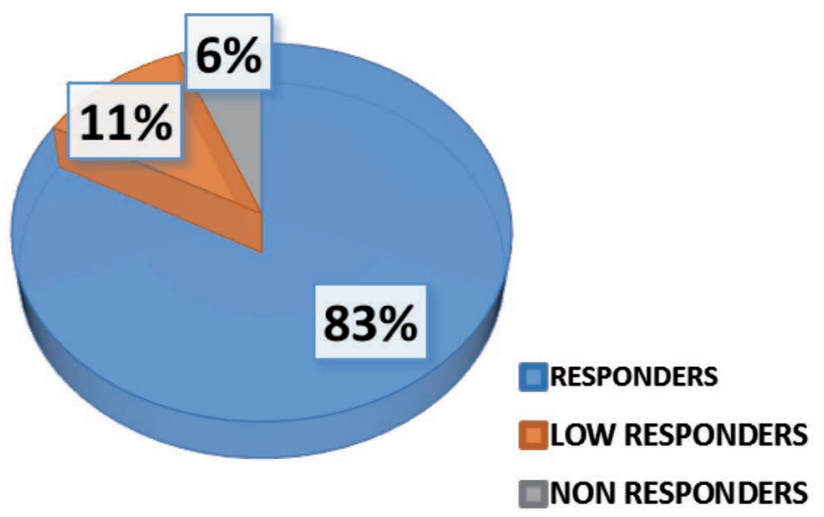

Figure 2. The administration of methadone $0.1 \%$ has produced $82.82 \%$ of responders subjects, $11.08 \%$ of low responders and $6.1 \%$ of non-responders. preponderance of male subjects (92\%). During this time, 1743 patients underwent integrated treatment: $68 \%$ were treated with $0.5 \%$ methadone, $2.8 \%$ with buprenorphine and $19.6 \%$ with suboxone.

Evaluating the pharmacological responses of the sample examined, it is possible to observe that the treatment with buprenorphine led to $71.98 \%$ of responders subjects, $23.52 \%$ low responders, $4.5 \%$ non-responders (Figure 1).

Instead, in Figure 2, we can see that the administration of methadone $0.1 \%$ has produced $82.82 \%$ of responders subjects, $11.08 \%$ of low responders and $6.1 \%$ of non-responders.

The $68 \%$ of patients, as mentioned above, were treated with methadone $0.5 \%$. This therapy has brought other important results: $88.98 \%$ of responders subjects, $7.8 \%$ of low responders, $3.22 \%$ of non-responders. As we can see in figure 3, thanks to this treatment, there has been a considerable increase in responders and a decrease in non-responders.

Finally, the last treatment was based on the administration of suboxone: through this type of treatment, we obtained $86.34 \%$ of responders subjects, $9.84 \%$ of low responders and $3.82 \%$ of nonresponders (Figure 4).

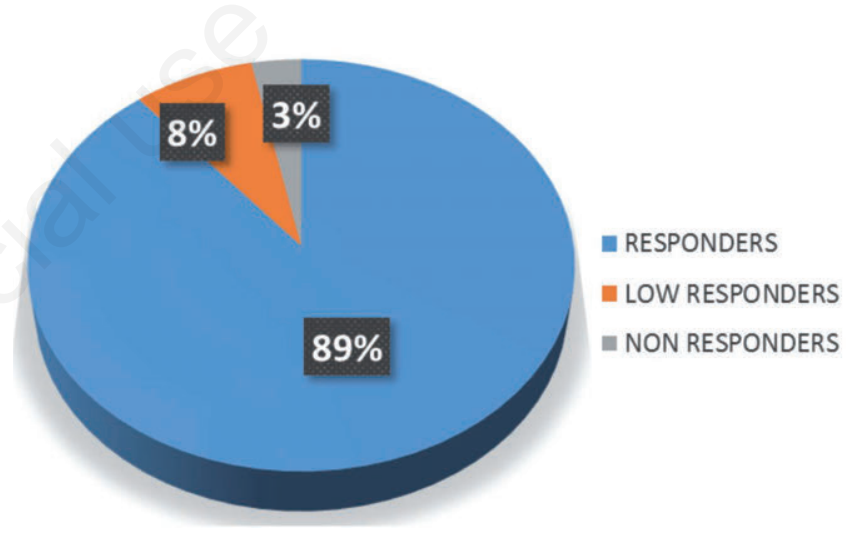

Figure 3. The treatment with methadone $0.5 \%$ led to: $88.98 \%$ of responders subjects, $7.8 \%$ of low responders, $3.22 \%$ of nonresponders.

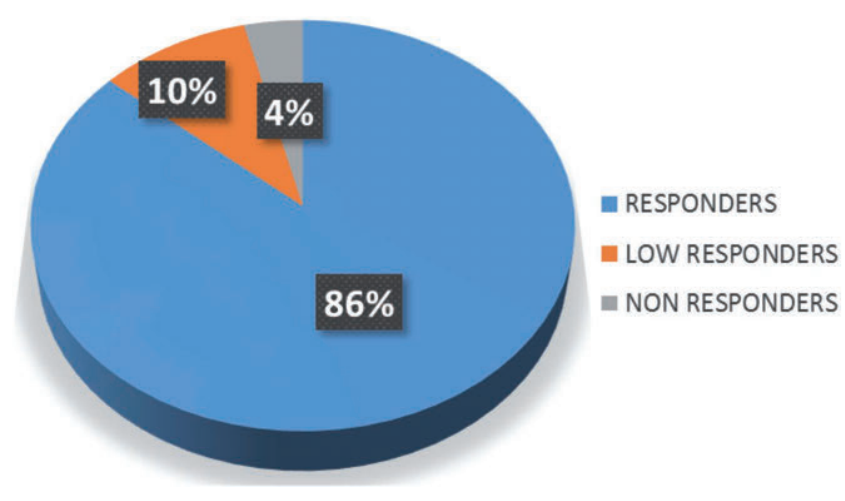

Figure 4. The graph shows $86.34 \%$ of responders subjects, $9.84 \%$ of low responders and $3.82 \%$ of non-responders obtained through the treatment based on the administration of suboxone. 


\section{Conclusions}

The treatment of heroin addiction is never exclusively pharmacological, but it is also true that drugs are almost always essential to guarantee any other intervention.

From the graphic elaboration of the data we highlight that the pharmacological substitutive treatment with $0.5 \%$ Methadone and the one with Suboxone gave the best results: for this reason, they were the two most used pharmacological therapies at the Ser.T of Caltanissetta during the analyzed period. However, it must be underlined that the patients treated with $0.5 \%$ Methadone were in a higher percentage of responders than those treated with Suboxone; in addition, with Metadone $0.5 \%$, in percentage, there were fewer low responders and non-responders patients.

So, Methadone is now the most widely used drug in heroin dissolution and this is mainly due to its ability to reduce craving, especially in "hard core" heroin addicts. However, the problem of "safety of use" remains; problem that is not present in Suboxone therapy, in which therapeutic efficacy and safety of use are equivalent. This is why the Suboxone is increasingly used, mainly on so-called "naive" patients, at the first approach to heroin and with an intermediate degree of dependency.
1. Faralli C, Morini G, Pacifici R, Zuccaio P. [Consumo di droghe in Italia - dati e statistiche.] Istituto superiore di sanità: osservatorio fumo, alcol e droga, 2008. [Article in Italian]. Available from: http://old.iss.it/drog/index.php?id=64\&tipo=26.

2. Europeran Monitoring Centre for Drugs and Drug Addiction (EMCDDA). European drug report. Lisbon, 2017.

3. Dipartimento politiche antidroga. Presidenza del Consiglio dei Ministri. [Relazione annuale al parlamento 2017 sullo stato delle tossicodipendenze in Italia, 2017.] Available from: http://www.politicheantidroga.gov.it/media/2153/relazione-alparlamento 2017.pdf. [Website in Italian].

4. Venturella F, Cancellieri G, Giammanco M, Di Marco P, Catania F, Liga AV. Amateur doping: a survey on Sicilian population. J Biol Res 2019;92:8238.

5. Venturella F, Cancellieri G, Giammanco M, Liga AV. Statistical analysis of a survey about diffusion of binge drinking and drunkorexia among students in Palermo. J Biol Res 2018;91:74-6.

6. Venturella F, Spada E, Tumbarello MC. Suboxone efficacy in treating drug addiction: comparison with methadone and monitoring of patients in therapy at SerT of Marsala - 90th SIBS National Congress on Experimental biology in basic and applied research to the environment and human health. Trapani, Italy, 27-28 October 2017. Abstract Book. J Biol Res 90:s1

7. Cole MD, Caddy B. The analysis of drug of abuse: an instruction manual. CRC Press, 1995. 